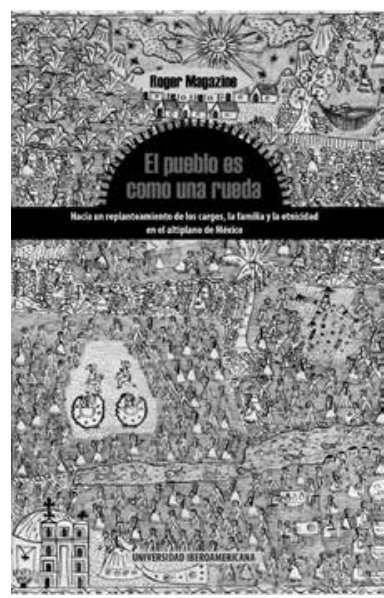

To Invent Persons

PedRo Pitarch

Universidad Complutense de Madrid,

Madrid, España

petul@ghis.ucm.es

Desacatos 55 ,

septiembre-diciembre 2017, pp. 196-201
- El pueblo es como una rueda. Hacia

un replanteamiento de los cargos,

la familia y la etnicidad en el altiplano

de México

Roger MAgAZINE, 2015

Universidad Iberoamericana, México

\section{Inventar personas}

\author{
PEDRO PITARCH
}

ste libro presenta un replanteamiento del sistema de cargos, la familia y la etnicidad en la región del altiplano de México. Dicho así, parece ambicioso, pero en realidad es un trabajo más ambicioso aún: es un intento de repensar aspectos cruciales de la socialidad del México rural. Lo importante aquí es que lo logra.

Tepetlaoxtoc, uno de tantos pueblos prácticamente aspirados por el crecimiento de la Ciudad de México, no es un lugar propiamente campesino y tampoco indígena. El vertiginoso desarrollo industrial y administrativo de la capital desde la década de 1940 atrajo a la mayor parte de la población y el pueblo quedó casi vacío. Con las crisis de las décadas de 1980 y 1990, los antiguos vecinos perdieron sus empleos y muchos retornaron, lo cual ofreció la oportunidad de reinventar en parte la vida comunitaria. El sistema de fiestas y cargos fue revitalizado y ampliado para cumplir el deseo de participación de los emigrantes retornados. El pueblo es como una rueda es una etnografía de la vida social renovada de Tepetlaoxtoc como resultado de la compleja relación que mantiene con la Ciudad de México. Una vida basada en valores, que los vecinos plantean como opuestos a lo que consideran propios de la vida social urbana, caracterizada por el individualismo y el interés por la acumulación de bienes. La investigación de Magazine se interesa menos por lo que 
se entiende en general por cultura que por lo que en la literatura en inglés se conoce como sociality: un modo de entender situaciones etnográficas por medio de la cualidad de las relaciones sociales conforme éstas son entendidas por los participantes. Desde este punto de vista, el libro prolonga la rica tradición de estudio de la sociología local rural mexicana, aunque, como veremos, su inspiración teórica tiene un origen muy distinto y sus conclusiones resultan también profundamente diferentes. Tiene tres capítulos centrales: "La fiesta se hace entre todos: para un replanteamiento de las fiestas y los cargos", "La ayuda entre y en el seno de las familias" y "Problemas de "etnicidad' y 'modernización””. En mi opinión, el más importante es el primero.

El "sistema de fiestas" y los "cargos" asociados a ellas son, por supuesto, un locus clásico de la etnografía mesoamericana. Desde los primeros estudios de comunidad, la discusión sobre qué es y para qué sirve el sistema de cargos no sólo ha permitido describir el funcionamiento de las comunidades indígenas y rurales de México y Guatemala, sino que, sobre todo, ha facilitado su definición según las orientaciones teóricas del momento. No sería difícil hacer una historia de las corrientes de la antropología mesoamericanista de acuerdo con las variaciones en la interpretación de las fiestas y cargos: una economía de prestigio que sostiene la continuidad cultural indígena (Tax, 1937), una forma de "cerrar" la comunidad y mantener fuera el mundo capitalista en general (Wolf, 1955), un medio de implicar a todos los miembros de la comunidad, redistribuir los recursos y reducir las desigualdades internas (Cancian, 1965), fundamento de una "ecología colonial” (Smith, 1977), un sistema que fuerza la reserva de mano de obra indígena a trabajar en la fincas de agricultura comercial (Rus y Wasserstrom, 1980), una forma de mantener la identidad y una cosmovisión distintivas (Medina, 2007). La discusión sobre la función del sistema de cargos produjo algunas polémicas teóricas que, como suele suceder en la antropología mesoamericanista, antes que resolverse en uno $\mathrm{u}$ otro sentido más bien se desvanecieron por indiferencia. Aquello que en un momento dado se presenta como una cuestión decisiva, luego pierde valor explicativo. Es probable que cuando las polémicas no se decantan de un lado u otro, la cuestión no estribe tanto en las respuestas dadas cuanto en la naturaleza misma del "problema". Desde hace algún tiempo, los "cargos" casi no habían sido objeto de estudio directo en la etnografía mesoamericana, en parte, sin duda, porque el sistema de cargos ha perdido centralidad en la vida comunitaria, pero también, cabe pensar, porque las fiestas y cargos en tanto problema sociológico han perdido su pertinencia.

El enfoque de Roger Magazine es distinto. Por una parte, no se interesa por el sistema de cargos como problema en sí mismo, sino como un dominio entre otros para repensar la cuestión de la socialidad rural de las tierras altas de México. Dicho de otro modo, no vuelve propiamente sobre la cuestión de los cargos para proporcionar una nueva interpretación, sino que éstos le sirven como medio para tratar cuestiones de lógica social. Por otra parte, en contraste con los trabajos anteriores tomados en conjunto, su punto de partida son las propias racionalizaciones de los vecinos de Tepetlaoxtoc. Magazine se interesa claramente — no retóricamente- por conceptualizar tanto las prácticas como los entendimientos concretos de éstas. Una antropología local, pues, que difiere en sustancia de la sociología académica anterior sobre los cargos.

La motivación de los cargos no reside tanto en celebrar la fiesta como en involucrarse con diligencia en su organización. Esto sonará en cierto modo familiar a los etnógrafos con experiencia, por más que rara vez se exprese con claridad: la atención se presta a la preparación del evento y al modo en que se desarrolla la actividad de las personas que lo impulsan. La principal diferencia que Magazine identifica entre las explicaciones de sus informantes y la 
literatura previa sobre los cargos y la fiesta concierne, pues, a la motivación del patrocinio individual y colectivo. Lo que enfatizan los vecinos de Tepetlaoxtoc es - y éste es el núcleo del argumento de Magazine - la necesidad de animar a los otros a participar, es decir, la práctica personal de llevar a los demás a realizar acciones consideradas socialmente valiosas. Esto significa que, en el caso de los cargos, el esfuerzo de los mayordomos no se concentra tanto en procurar cosas - la parafernalia ceremonial, la comida o la fiesta misma-, como en hacer que los vecinos se involucren en las actividades que esas cosas presuponen. No es que estos objetos y acciones no sean importantes, pero lo que resulta decisivo, aquello que define la esencia de toda la acción, es la capacidad para crear lo que Magazine llama un "estado subjetivo" de entusiasmo en los demás, que permita que se involucren de manera activa en la fiesta. La imagen que utilizan los lugareños para explicar cómo se organiza una fiesta es: "el pueblo es como una rueda. Los habitantes conforman la rueda misma, los compañeros o ayudantes del mayordomo son los rayos de la rueda, y el mayordomo es quien logra que la rueda empiece a girar" (p. 20).

El mayordomo pone en marcha la rueda, produce el impulso inicial, pero, como veremos, una vez obtenido éste, el movimiento pertenece a todo el pueblo. La principal tarea del mayordomo, mientras realiza un sinnúmero de visitas a las casas del pueblo, consiste en tratar de revertir, con la mayor cortesía posible, la renuencia inicial de los vecinos a involucrarse en las actividades y transmitirles ese "estado subjetivo activo" de deseo de colaborar. Podría decirse, siguiendo la metáfora de la rueda, que ese estado subjetivo activo es la fuerza que hace que se mueva la rueda, esto es, el pueblo, y una vez superada la inercia del estado de reposo, dicha fuerza - el estado subjetivo - se transmite a todos los participantes. Magazine insiste en que esto no se plantea como un modo de sacrificarse por el bien común o como un gesto que concede prestigio al mayordomo, sino como un ejercicio que revela la interdependencia de los vecinos. De hecho, el autor privilegia el uso del término "reconocimiento" sobre el de "prestigio", mucho más común en literatura sobre cargos, porque los vecinos hablan de "ser reconocidos" por su participación. Aquellos que son reconocidos por su "gusto" por participar son "buscados por otros" debido a que su participación hace germinar ese mismo gusto en los demás. El mayordomo produce algo de valor, esto es, la participación de otros, pero en última instancia este valor no le pertenece a él, sino al resto de los agentes. No se trata de obtener estatus, poder o una suerte de capital simbólico que pueda ser trocado más adelante por otra clase de beneficio, porque en definitiva no es el mayordomo quien hace la fiesta. "La fiesta se hace entre todos", dicen en el pueblo, lo cual requiere que todos se inciten de manera recíproca, pues cada agente depende de los demás como principio de sus acciones. Es justamente este delicado juego de elicitación mutua, de interdependencia, de incitación-actividad, lo que los vecinos de Tepetlaoxtoc encuentran ausente y critican del medio urbano de la Ciudad de México.

Como se ve, Magazine introduce dos conceptos clave extraños a la tradición etnográfica mesoamericana: "interdependencia" y "producción de subjetividad activa”. El primero procura capturar la afirmación insistente de los vecinos de que la fiesta u otras actividades públicas se hacen "entre todos". No se trata sólo de producir un esfuerzo en común, observa Magazine, sino de reconocer que las personas mismas están entrelazadas por la necesidad mutua de producir la acción deseada. Por su parte, la expresión "producción de subjetividad activa" se refiere al modo específico en el que las personas y sus acciones se entrelazan, un cierto estado de ánimo requerido para actuar, transmitido de unos a otros de un modo casi contagioso. En este sentido, Magazine subraya la aparente contradicción de que los lugareños atribuyan la participación en los cargos 
tanto a una obligación como a una acción voluntaria. Es una obligación porque al principio todos rechazan participar o se muestran reticentes a aceptar un cargo, pero una vez que éste es aceptado, se produce ese nuevo estado subjetivo que lleva a hacer las cosas "por gusto". Podría decirse, sin demasiado contrasentido, que las personas son forzadas a aceptar de manera voluntaria el cargo. La importancia de esta participación voluntaria e idealmente entusiasta reside en demostrar que un vecino no interviene como objeto si no como sujeto.

La perspectiva que subyace al enfoque de Magazine es la teoría de la agencia melanesia, como ha sido desarrollada por Roy Wagner en The Invention of Culture (1981) y Marilyn Strathern en The Gender of the Gift (1988). Dos obras clásicas, que increíblemente no han sido traducidas al español. De Wagner, toma la idea —esencial, en mi opinión, para entender las culturas indígenas y campesinas de México- de la distribución inversa de lo dado y lo artificial en lo que llama culturas "diferenciantes". Si para la cultura occidental la convención —el orden social, el parentesco, las normas sociales, el lenguaje, etc. - representa el dominio artificial del universo, aquel que cae bajo la responsabilidad de la acción humana, para gente como los vecinos de Tepetlaoxtoc, la convención es algo dado, innato, que forma parte de los principios inmanentes del universo. Strathern (1988) sigue este principio en su observación de que el intercambio de dones en Melanesia no concierne a la producción de esos bienes sino a la producción de agencia. No son las personas las que producen las relaciones sociales, sino las relaciones sociales las que producen personas. Las relaciones sociales pertenecen al polo de aquello que es dado y de lo que se trata es de producir personas, esto es, agentes capaces de llevar a cabo acciones.

Las implicaciones para el argumento de Magazine son claras. Desde el punto de vista local de Tepetlaoxtoc, las fiestas y los cargos están dirigidos a producir un contexto en el que unas personas pueden actuar sobre otras. Si bien el autor no extrae directamente esta conclusión, podría decirse que llegan a producir a las personas mismas. Aquí podríamos abandonar el término "producir" y sustituirlo quizá por "inventar” en el sentido de Wagner (1981): invención no como artificio o fantasía sino en su sentido de innovación y creatividad, lo que se innova es la persona misma. En definitiva, son las personas y no las cosas o actividades per se lo que importa en este contexto. Para tomar un ejemplo de mi propio trabajo entre los tseltales, las relaciones sociales se orientan a engendrar respeto, y no el respeto a producir o facilitar las relaciones sociales. De ahí la importancia de la idea de "respeto" en el discurso político indígena (Pitarch, 2013). Esto es, si entiendo bien, es el principio de socialidad que rige en Tepetlaoxtoc: las personas no están completas ni actúan de manera autónoma, sino que deben ser inducidas e inducir a su vez a otros para llevar a cabo una actividad como la fiesta.

De los otros dos capítulos centrales, uno es sobre las relaciones familiares y el otro acerca de cuestiones de modernización e identidad colectiva. Ambos desarrollan, en esencia, este mismo argumento. La familia interesa, no como un medio de reproducción biológica y social de personas, sino como un marco de "producción continua de subjetividad activa”. Esto quiere decir que la familia, en lugar de ser un dominio dirigido a socializar unos niños nacidos en estado de naturaleza, esto es, de moldear una subjetividad innata, es vista mejor como un lugar de desarrollo de la interdependencia: “de trabajar juntos”, según una expresión de Catharine Good, citada por Magazine. No se "pertenece" a la familia, se actúa en su seno para elaborar una subjetividad basada en la ayuda mutua y la deuda contraída. Otro tanto afirma Magazine de la "cultura tradicional”, aquello que se entiende por lo general como los modos de identificación colectiva y sus implicaciones para el cambio y la modernización culturales. Si conforme a la interpretación etnográfica 
convencional, las fiestas producen "cultura", "sociedad" y "tradición”, es decir, todo lo que diferencia la comunidad de la vida caracterizada como moderna o urbana, la interpretación local supone que la sociedad es dada — se encuentra ya allí, es algo natural, por así decir-y de lo que se trata es de "hacer participantes", inventar sujetos. Para la gente de Tepetlaoxtoc, observa Magazine, la modernidad es una especie de conducto que permite innovar a la persona, experimentar nuevos modos de motivar y ser motivado por los otros.

Hay, sin embargo, un aspecto en el que disiento de Roger Magazine. Él limita el ámbito geográfico de aplicabilidad de su tesis a la zona rural del Altiplano de México. Es una precaución comprensible. Pero como afirmaba al comienzo de este comentario, la tesis del libro — no los ejemplos etnográficos, que son desde luego locales- es suficientemente genérica como para ampliar su ámbito a la vida rural mexicana más general. De hecho, como hemos visto, Magazine se basa en premisas tan excéntricas como las de la teoría melanesia de la agencia, que sin embargo permiten repensar actividades locales como las Tepetlaoxtoc. Es más, las explicaciones de Magazine pueden contribuir a comprender también mucho de la vida social entre los sectores populares urbanos, por ejemplo, de la Ciudad de México. Después de todo, una ciudad como México está hecha principalmente de migrantes procedentes de lugares como Tepetlaoxtoc. Magazine parece renuente a extender esta posibilidad, y quizá se deba a la caracterización que hacen sus informantes sobre la naturaleza "individualista" y "materialista" de la vida urbana. Creo que, en este punto, Magazine podría separarse de las caracterizaciones locales. Como hemos visto, el signo diacrítico empleado por los pobladores para diferenciarse de la gente de la ciudad no es la cultura o la tradición, sino los modos de socialidad. Yo interpreto esto como un recurso de diferenciación y singularización. Dicho de otro modo, una descripción de la socialidad de los barrios de la Ciudad de México podría fundarse en una etnografía local semejante a la de Magazine y no en la caracterización de los pobladores de Tepetlaoxtoc. Estos últimos, de hecho, parecen haber adoptado en este punto — quizá como resultado de su estancia en la Ciudad de México- un poco de la retórica del comunitarismo rural perdido, propia de la clase media.

Sugiero, pues, que la lógica de la participación que revela el trabajo de Magazine posee unas posibilidades mucho más amplias de lo que el propio autor está dispuesto a admitir en la conclusión del libro. La atención a un tipo de socialidad dirigida, no a la producción de cosas y acontecimientos, sino a la invención de personas permite redistribuir los dominios de la etnografía. Permite, por ejemplo, reconsiderar la insidiosa distinción tradicional/moderno para reformularla en términos del contraste invención de personas $v s$. producción de bienes. Semejante redistribución subsume a su vez distinciones asentadas con firmeza. La línea de distinción no tiene por qué encontrarse entre los dominios rural y urbano, entre indígena y no indígena, entre tradicional y moderno, sino en un modo de socialidad dirigido a producir personas o bien a producir cosas, es decir, sujetos u objetos. El reconocimiento de una racionalidad social discordante de la capitalista, pero no reducible a su vez a categorías como indígena, campesino o tradicional, traza un mapa alternativo para la antropología mesoamericanista.

La existencia de unos presupuestos comunes acerca de ciertas motivaciones sociales permite que poblaciones culturalmente distintas —indígenas y no indígenas, por ejemplo- puedan relacionarse con relativa facilidad. En cambio, obstaculiza la posibilidad de "coactividad" entre personas que no los comparten, por ejemplo, gente de barrios populares y de empresas guiadas por una racionalidad capitalista — con “empleados del mes”, por así decir-. El pueblo es como una rueda prueba una vez más el poder subversivo de la etnografía. D 


\section{Bibliografía}

Cancian, Frank, 1965, Economics and Prestige in a Maya Community, Stanford, University Press, Stanford.

Good Eshelman, Catharine, 2004, "La vida ceremonial en la construcción de la cultura: procesos de identidad entre los nahuas de Guerrero", en Johanna Broda y Catherine Good Eshelman (eds.), Historia y vida ceremonial en las comunidades mesoamericanas: Ios ritos agrícolas, Instituto Nacional de Antropología e Historia/Universidad Nacional Autónoma de México, México, pp. 127-149.

Medina Hernández, Andrés, 2007, "Los pueblos originarios del sur del Distrito Federal: una primera mirada etnográfica”, en Andrés Medina Hernández (ed.), La memoria negada de la ciudad de México: sus pueblos originarios, Universidad Nacional Autónoma de México/ Universidad Autónoma de la Ciudad de México, México.

Pitarch, Pedro, 2013, "Los extravíos de la traducción. Una versión tzeltal de la Declaración Universal de los Derechos Humanos”, en Pedro Pitarch, La cara oculta del pliegue, Artes de México/Consejo Nacional para la Cultura y las Artes, México.

Rus, Jan y Robert Wasserstrom, 1980, "Civil-Religious Hierarchies in Central Chiapas: A Critical Perspective”, en American Ethnologist, vol. 7, núm. 3, pp. 466-478.

Smith, Waldemar, 1977, The Fiesta System and Economic Change, Columbia University Press, Nueva York.

Strathern, Marilyn, 1988, The Gender of the Gift: Problems with Women and Problems with Society in Melanesia, University of California Press, Berkeley.

Tax, Sol, 1937, "The Municipios of the Midwestern Highlands of Guatemala”, en American Anthropologist, vol. 39, núm. 3, pp. 423-444.

Wagner, Roy, 1981, The Invention of Culture, University of Chicago Press, Chicago.

Wolf, Eric R., 1955, "The Types of Latin American Peasantry", en American Anthropologist, vol. 57, núm. 3, pp. 452-471. 